\title{
Civil Reality? Simulation Experiments on the Impact of Civil War in a Realist World
}

\author{
Richard J. Stoll \\ Department of Political Science \\ Rice University \\ Houston, Texas, USA
}

\begin{abstract}
The most widely used theoretical framework in international relations is realism. Realism takes many forms, and there have been hundreds of writings on the topic. In the United States, the two most popular exemplars of realism are Morgenthau (Morgenthau \& Thompson, 1985; original 1948) and Waltz (1979). There is no systematic attempt to incorporate civil wars into the realist framework. In this paper, we use a computer simulation to explore the impact of a state's civil war experience on its interstate war experience. The results suggest that a state's civil war experience can have an impact on its interstate war experience.
\end{abstract}

Keywords civil war, realism, computer simulation, experiment

Realism is the most widely used theoretical framework in international relations. Scholars and practitioners using its many variants have focused on external (interstate) conflict. But there is little or no discussion in that literature about the impact of internal conflict on the external relations of states. However, as will be shown below, internal conflicts (civil wars) are far more prevalent than external conflicts. Given their frequency, as well as their severity, it seems reasonable to expect that internal conflicts would have an impact on a state's external behavior. But if one assumes that realism describes the behavior of states, what are we to conclude about the impact of civil wars on the propensity of a state to become involved in interstate wars?

In this paper, we will try to shed some light on the impact of internal conflict in a realist world. We do so by using a computer simulation called EARTH (Exploring Alternative Realpolitik Theses). This simulation is the direct descendant of a simulation developed by Stuart Bremer and Mike Mihalka (1977); there was no formal name for this simulation, but its authors referred to it as "the Coop."

We begin this paper by looking at the relative frequencies of civil (intrastate) and interstate wars through time to appreciate the dimensions of the problem for realists. We then make a brief attempt to summarize the field of realist thought (a somewhat daunting task). This is followed by a discussion of the utility of simulation to examine such questions 
TABLE 1 Relative frequencies of interstate and civil wars, 1816-1997

\begin{tabular}{lccccc}
\hline & \multicolumn{2}{c}{ Interstate wars } & & \multicolumn{2}{c}{ Intrastate wars } \\
\cline { 2 - 3 } \cline { 6 - 6 } Years & Number & Percentage & & Number & Percentage \\
\hline $1816-1914$ & 40 & 32.3 & & 84 & 67.7 \\
$1919-1939$ & 15 & 41.7 & & 21 & 58.3 \\
$1946-1989$ & 22 & 21.8 & & 79 & 78.2 \\
$1990-1997$ & 1 & 4.0 & & 24 & 96.0 \\
\hline
\end{tabular}

Note: Table excludes wars which began during the World Wars.

and the introduction of the EARTH simulation. Next we describe the runs we conducted to explore this question and what the subsequent statistical analysis revealed about the impact of civil wars in a realist world.

\section{Interstate Wars and Civil Wars: Relative Frequencies}

Before embarking on this theoretical investigation, let us take a quick look at the frequency of both types of war. In Table 1 we display the relative frequencies of interstate and intrastate wars from 1816 through 1997 taken from the Correlates of War Project data (Sarkees, 2000). We have divided these data into several time periods. The first represents the period of time from the end of the Napoleonic Wars to the outbreak of World War I, the second is the interwar period, the third is the Cold War, and the fourth is the post-Cold War period (up to the end of the dataset). ${ }^{1}$

The figures in the table lead to a very clear conclusion. For the time period covered in the dataset, intrastate war has always been more common than interstate war. And through time, the trend is for the imbalance in favor of intrastate war to increase; in the post-Cold War period (through 1997) there is only a single interstate war. The implication is clear: large- scale internal conflict (civil war) is a more common occurrence than large-scale external conflict.

\section{Realism: Its Many Variants}

Ultimately we want to talk about the role of war in a realist world. But before that, we have to provide a basic overview of realist thought. Realism is seen as a fairly monolithic approach to international relations, by both scholars and policy makers. It is common for realist writers to assert that realism is based on a few key assumptions. But a closer look at the writings of realists shows a great deal more diversity than is commonly assumed. ${ }^{2}$

\footnotetext{
${ }^{1}$ Note that the periods of time during the World Wars are excluded from the table.

${ }^{2}$ One example is in the introductory chapter of Wayman and Diehl's edited volume Reconstructing Realpolitik. Ina table they indicate how each of the contributors to the book treat what they term "the Common Realist Propositions" (Wayman \& Diehl, 1994, 9). There
} 
Most students of international relations see two main schools of realist thought: classical realism (as epitomized by Morgenthau and Thompson, 1985; the original was Morgenthau, 1948) and neorealism (as epitomized by Waltz, 1979). Space prohibits a full-blown (or even a comprehensive) review of this vast literature. But we will briefly cover what we take to be the essential features of the main components of each school of thought.

TABLE 2 Categorization of realist writings

\begin{tabular}{lll}
\hline & \multicolumn{1}{c}{ Extreme } & \multicolumn{1}{c}{ Moderate } \\
\hline Optimist & Automatic stabilization & Power balancing \\
Pessimist & Universal empire & Cycles of concentration \\
\hline
\end{tabular}

Note: Adapted from Tble 6-2, Cusack and Stoll (1990, 191).

\section{Neorealism}

Waltz (1979) laid the foundation for neorealism. It is probably fair to say that, at least among American scholars, neorealism is the dominant realist approach in use today. There are two main variants (Mearsheimer, 2001, 17-22): offensive realism and defensive realism. In offensive realism, states seek to maximize their power and strive to become hegemons. In defensive realism, the goal of states is to survive. Under defensive realism, states seek to preserve (or restore) the balance of power within the system. But under offensive realism, states seek to disrupt the balance of power (in their favor, of course).

\section{Classical Realism}

The literature of classical realism is far larger and far more amorphous than that of neorealism. For example, the neorealism literature has a clear beginning: the writings of Waltz. And for the most part, neorealists selfidentify. But the situation with regards to realist writings is far more complicated. Some realists would claim Thucydides' account of the Peloponnesian War (Strassler, 1998) as a realist account (and even call him the first realist), and in truth, much of what he discusses is consistent with realist accounts. But clearly, he did not identify himself as a realist and he was not interested in general theory; he wanted to describe and understand the Peloponnesian War. Should we view his work as realist writing? And even if we come to some sort of consensus on whether individual scholars are realists, how can we organize these writings?

Completing such a task cannot be done within the confines of a single paper. In fact, one can make a case that the task is impossible. In the course

are two interesting features to this table. First, the authors list 15 propositions (note: some are variants of others). Fifteen is a large number of propositions for a theory. Second, only one assumption (states are key actors) is used by the authors of all nine chapters, and only two (states are rational, states enhance and maintain their own power) are used in more than half the chapters. This suggests that there is not a strong consensus among the authors of chapters in this book on the essence of realism. 
of developing $E A R T H$, we developed a categorization of the realist literature (Cusack \& Stoll, 1990, 19-62). Below we offer a brief synopsis of how we organized the literature.

We believe that realist writers ${ }^{3}$ can be located by their position on two dimensions. One dimension is defined by whether the writer believes that a system of states behaving according to realist principles will survive and prosper (and therefore, most of the individual states will survive), or whether it will collapse. The first group we call optimists, and the second group we call pessimists. The second dimension is defined by whether the writer takes an extreme view or a moderate view of the prospects of system survival. Table 2 displays how we identify each group of writers. We have labeled each cell of the table to reflect the essence of each category of realism.

The automatic stabilization category is analogous to the basic freemarket model of economics (although political scientists should remember that realist writings in this cat- egory can be found as early as the $\left.1700 \mathrm{~s}^{4}\right)$. In this perspective, every state is assumed to seek to maximize power. But if the actions of some states start to upset the entire system of states, others (motivated by their own self-interest) will act to restrain them. So, like the free market, the net result of individual actors striving to maximize their gains is a rough equilibrium among all states.

Power balancing is a less extreme version of automatic stabilization. Writers in the power balancing perspective believe that the self-interest in the automatic stabilization perspective, while an important regulating device, will not always be sufficient to prevent degeneration of the system. Something additional is required. Among writers in this tradition a variety of alternatives are proposed: clever diplomats capable of successfully fine-tuning the balance, an informal understanding that regardless of the ambitions of states, no state should be eliminated, or that one or more states act as balancers (a balancer seeks to preserve the system rather than to maintain or increase its own power). Regardless of the specific mechanism, these writers agree that self-interest is not enough to sustain the system, but that it can be sustained if one of these additional elements is present.

Realist writers who are extreme pessimists have a very simple view. In the long run, a system of states operating according to realist principles will collapse to a universal empire. The result may not be immediate, but ultimately nothing can prevent the complete dominance by a single state.

The final view is pessimistic but more moderate. Writers in this tradition believe that in a realist system, an empire will occur. But empires do not last forever. Ultimately they disintegrate, and a multistate system will

\footnotetext{
${ }^{3}$ The term "realist writers" is meant to encompass not only those who believe that realism provides an accurate description of the world, but others who view realism in a critical light.

${ }^{4}$ For example, Jean-Jacques Rousseau said the following about the unconscious manner in which the balance worked:
}

But whether we are aware of it or not, the balance continues to support itself without the aid of any special intervention: if it were to break for a moment on one side, it would soon restore itself on another so that, if the Princes who are accused of aiming at universal monarchy were in reality guilty of any such project, they gave more proof of ambition than of genius. (Quoted in Forsyth, 1970, 138) 
re-emerge. So the final realist perspective is that of cycles of concentration followed by periods of time in which a multistate system occurs.

\section{War in a Realist World: A Part of the Environment}

It is important to remember that realism (in all its variants) is not a theory about why wars happen. Rather, it is a theory about the behavior of states and/or systems of states in a realist environment. And war is part of this environment. It is an acceptable means for states to pursue their interests. This does not mean that war will necessarily be a frequent event, but wars can be expected to occur in a functioning realist system. ${ }^{5}$

\section{Realism and Civil Wars: A Theoretical Chasm?}

At the theoretical level, realism (in its many forms) is the most widely used framework in international relations. And as shown earlier, intrastate wars are far more common than interstate wars. So is there an intersection between realist theory and intrastate wars? It is certainly not present in the work of Morgenthau and Waltz, the two exemplars of realist theory.

Morgenthau says that the existence and destiny of the United States were more deeply affected by the domestic events of the Civil War than by the international policies leading up to, and evolving from, the Mexican War, the Spanish-American War, and the Roosevelt corollary to the Monroe Doctrine (Morgenthau \& Thompson, 1985, 26).

There are three remaining references to the American Civil War in Morgenthau, ${ }^{6}$ but none relates the American Civil War to international relations. As well, Morgenthau makes no general comments about the impact of civil war in a realist system or on a realist state.

Like Morgenthau, Waltz says little about civil wars. He does note that although we often assume that the threat of violence distinguishes international affairs from national affairs, this is not always the case. He discusses some very destructive civil wars, and he ends his discussion with the following comment: "We easily lose sight of the fact that struggles to achieve and maintain power, to establish order, and to contrive a kind of justice within states, may be bloodier than wars among them" (Waltz, 1979, 103).

However, like Morgenthau, Waltz does not move beyond this statement. Thus, neither of the two most prominent realist writers of the post-World War II era incorporates internal war into their realist theories.

There is a great chasm between internal war and the most well-known theories of realism. Starr's review of the linkage between internal and external conflict (Starr, 1994) makes the same point (although his review is

\footnotetext{
${ }^{5}$ Even if a state seeks only to preserve its power position (e.g., as would be the case for most states under defensive realism), there may be times when the only way that it can achieve this goal is to go to war

${ }^{6}$ On pages 278,408 , and 530 of Morgenthau and Thompson (1985).
} 
much broader in scope than the focus of this paper). There is a significant disconnect between the behavior of states and the most prominent theoretical construct in international relations. Since the end of the Napoleonic era, civil wars have been more common - in most time periods much more common - than interstate wars. But realism, no matter what the variant, has nothing to say about these wars and their impact on interstate relations.

This chasm deserves a great deal of attention. The full implications of it cannot be understood without a significant effort. What follows is an initial effort to integrate civil wars into a realist framefork. We will use computer simulation to explore this theoretical void. Specifically we seek to begin to understand whether a state's involvement in civil wars has an impact on its interstate war involvement. ${ }^{7}$ Before we deal with the substantive issues of this paper, we need to discuss why computer simulation can be a useful tool to explore theoretical issues.

\section{The Utility of Computer Simulation}

Computer simulation is not just a single technique or approach to modeling. ${ }^{8}$ But despite the differences between types of simulation, there are several features of this approach to model building that distinguish it from other formal methods of modeling.

First, computer simulations can be very large and complex. Of course, it is always desirable that our models be much simpler than reality. Occam's razor leads us to prefer a simpler model to a more complex one, but only as long as they both appear to explain the same content. But other forms of modeling may be too simple and may abstract away important

\footnotetext{
${ }^{7}$ It should be noted that Simon and Starr $(1996,2000)$ also build and run computer simulations looking at the interaction between the allocation of resources by a state and its efforts to avoid both internal and external conflict. It appears that this work was motivated by Starr's (1994) work, which reviewed the linkage between internal and external conflict noted above. There are a number of parallels between their simulation and EARTH with respect to internal and external conflict and allocation decisions made by states to forestall both forms of conflict. But Simon and Starr's simulations are not explicitly based on a realist framework. This is not a criticism; that was not their intent. ${ }^{8}$ Benoit offers the following list of types of computer simulation (but comments that it is "illustrative rather than exhaustive"): (1) Agent models. In agent models, individual actors (agents)are programmed to control their own actions based on information (perceptions) about their environment. (2) Evolutionary models. In these models, the programmed actors can change their parameters or their structure as the actors learn from the environment. (3) Cellular automata models. Benoit refers to these as "stripped down agents." The focus of these models is the emergent patterns that appear at the aggregate level as multiple agents follow rules through multiple iterations. (4) System dynamics and related models. These models use a system of difference and/or differential equations. The goal is to predict macro-level outcomes. (5) Microanalytical simulation models. In these models, the focus is on the micro-level agents. Successive generations of individual agents are followed in order to predict the future of the system (Benoit, 2001, 14).
} 
aspects of the reality that we are seeking to understand. Consider the following comment by two well-known formal modelers of international systems:

Realist-neoliberal debates, then, are readily formalized [using game theory], but we should not delude ourselves into believing that we have overcome the hardest problems. First, our model does not take account of investment and endogenous resources growth. Second, we ignore the costs of conflict. Finally, our model ignores uncertainty and misperception. (Niou \& Ordeshook, 1991, 510)

I would note that $E A R T H$ includes all these features. As well, the typical study using EARTH involves a state system that begins with 98 states. ${ }^{9}$ Formal models (and traditional analysis) of realist systems generally focus on only a handful of actors (perhaps just examining the major powers). We believe this is because it would be very difficult (even impossible) to deal with large systems using these approaches. But it is not difficult to model large systems with a computer simulation.

As well, examining the long-run behavior of a series of actors (for example, the long- term behavior of a system of states or the long-term prospects for individual states) is not difficult in a simulation. You simply run it for a greater number of iterations. But determining the results of a large number of iterations in a formal model can be quite difficult.

Another advantage of computer simulation is that a "working model" is built. Consequently, in a computer simulation one can observe how each link in a model relates to the next link. In essence, every computer model is dynamic.

By including random elements, ${ }^{10}$ computer simulation also allows the researcher to approximate parameter values when she does not have more specific information. That is, if the researcher does not have enough information to specify a particular value, she can instead specify a mean value and a standard depiation for that parameter and draw a random number from this distribution. 11 Of course, this ability comes at a price. First, a number of runs must be conducted in order to ascertain the "typical" effect of that parameter. And this leads to the second cost that must be paid. If one uses a formal model, one can deduce the specific consequences of the model. But if one uses random elements in a computer simulation, then this is not possible; the best one can do is to discover the typical ("average") outcome of the simulation. Obviously, this is a less specific conclusion than one that can be reached by a formal model.

\footnotetext{
${ }^{9}$ The program is capable of systems initially as large as 6400 states.

${ }^{10}$ Not all simulations include random elements.

${ }^{11}$ This suggests that the random values are drawn from a normal distribution, but this need not be the case; the values can be drawn from a variety of distributions.

${ }^{12}$ The large amount of data produced by a simulation can also result in the researcher having to use statistical analysis to reach theoretical conclusions, as will be the case in this paper.
} 


\section{The EARTH Simulation}

EARTH is based on "the Coop" developed by Bremer and Mihalka (1977), but it incorporates a number of additional elements. ${ }^{13}$ Chapter 3 of Cusack and Stoll (1990) provides a more complete description of the EARTH simulation. In this article we provide only an overview of its components. ${ }^{14}$

\section{Initialization}

A number of parameters have to be initialized to run the simulation. The specification of both a mean and a standard deviation for the initial distribution of power in the system is one example. Altering this parameter allows the researcher to "create" systems that have an even distribution of power, or systems that have an uneven distribution of power. Each state has a physical location; in the case of EARTH, each of the original 98 states is a single hexagon. These are arranged into seven rows and fourteen columns. The appendix describes all the parameters necessary for a run.

\section{Civil War and Disintegration Phase}

Each iteration of the simulation begins with the civil war and disintegration phase. ${ }^{15}$ Civil wars can only occur in a state that occupies more than one territorial space (hexagon). A civil war is more likely to occur if the state has allocated too few resources to maintain internal security. The probability of a civil war is a function of the difference between the power the state has allocated for internal security and the minimum amount of power necessary for that state to maintain control. The further the actual allocation is below the minimum level, the more likely the state is to experience a civil war.

Once a civil war breaks out in a multihex state, the total number of hexagons within the state that are in revolt is determined stochastically. Once the total is calculated, individual hexagons are designated as being in revolt. This designation is based on three factors representing how costly it is for the state to control the hexagon. The more powerful the hexagon, the more likely it is to be in revolt. The further away a hexagon is from the

\footnotetext{
${ }^{13}$ With the immense growth in computer power, the ability to do a large number of computer runs at high speed "at home" has been greatly increased. Consequently, the ability to run large simulations is within the capability of anyone with a decent desktop computer. The original version of the simulation discussed here (Bremer and Mihalka's "the Coop") ran on a very large IBM mainframe, took a great deal of time, and, given the rationing of computing (through computer accounts), was only able to do a very small number of runs (perhaps less than 20 for the article). The original PC version of EARTH took 20 to 30 minutes (without the civil war component being activated). So the runs for a study could be done in a week or so. The current version (without the civil war component) will generally execute a run in less than a minute.

${ }^{14}$ This description of the simulation is based on Stoll (1999).

${ }^{15}$ It is possible to turn off the civil war and disintegration phase of EARTH.
} 
original hexagon of the state, the more likely the hexagon is to be in revolt. The shorter the time the hexagon has been part of the state, the more likely it is to be in revolt.

A war is then fought, pitting all the "loyal" hexagons of the state against all of the hexagons in revolt. All hexagons participating in the war lose a proportion of their power; this represents the costs of fighting the war. The outcome of the war is a function of the power ratio between the two sides. If the winning side is the loyal hexagons, the state's territory remains intact. If the revolt succeeds, the original state is broken up into two or more new states. Groups of contiguous hexagons that fought on the same side in the civil war form the new states.

\section{Dispute Onset}

The next phase of the simulation deals with the possible onset of a dispute. It begins by identifying the state that might initiate a dispute. The chances of a state being identified are equal to that state's proportion of all of the power in the system. ${ }^{16}$ Once the state is selected, it calculates the power relationship between itself and each of its neighboring states. ${ }^{17}$ If there is no neighbor over whom the state calculates it has a power advantage, no interstate conflict occurs in this iteration, and the simulation moves to the power adjustment phase. If there is one neighbor over whom it calculates it has a power advantage, the state initiates a dispute against this neighbor. If there is more than one neighbor over whom it calculates it has a power advantage, the state initiates a dispute against the weakest neighbor.

\section{Dispute Escalation}

After a dispute is initiated, there can be a number of rounds of alliance formation. This process begins with the target state calculating the power ratio between itself and the initiator. If the target calculates it is more powerful, it does not seek allies. If it calculates it is weaker, then it examines the power of all states that border its opponent. Based on these calculations, the target state asks some or all of these states to join it; the state makes offers seeking to build a minimal winning coalition against the initiator. Each state that receives a request to join the target makes its own calculation of the power balance that would occur between the initiator state and the target state along with its allies. If the state calculates that the target coalition

\footnotetext{
${ }^{16}$ All of the states in the simulation runs for this paper are primitive power seekers. That is, faced with an opportunity to begin or join a conflict, the state calculates whether it will be on the more powerful side. Three other types of state can be used in the simulation; for a discussion of all four types of state, see Cusack and Stoll (1990, 70-72).

${ }^{17}$ In the initialization for a simulation run, each state is assigned an accuracy in its ability to estimate its own power and an accuracy in its ability to estimate the power of other states. All state decisions are based on the calculated power (which can be in error), not on the actual power.
} 
would be stronger, it joins the coalition.

When the target finishes its coalition-building effort, the initiator engages in the same process of calculating the power balance between the two sides and, if necessary, seeking to build a minimal winning coalition of allies that is adjacent to the target. If the initiator is not able to build a minimal winning coalition, then the initiator ends the dispute and the simulation goes to the power adjustment phase. After the initiator finishes, the target is given a second opportunity to add allies. Once this final round is completed, a war is fought.

\section{War}

Wars last only a single iteration and end in victory for one side. The simulation has an option for wars to end in a tie, but that option was not turned on for the runs for this paper. The chances of the initiator winning the war are a function of the power ratio between the initiator and target coalitions (see Cusack \& Stoll, 1990, 76).

All the states that fought in the war lose some of their power; this represents the cost of fighting the war. ${ }^{18}$ The states on the losing side also have to give up an additional proportion of their power, and all of this is placed in a common "pool" of power. Members of the winning coalition receive a portion of this pool of power. Each member of the winning coalition receives the proportion of this pool that is equal to its proportion of the total power on the winning side.

The leader of the losing coalition (the original initiator or target state) also must give up territory. The number of hexagons that it gives up is a function of its size and the decisiveness of the defeat. In some cases, this state must give up all its territory, and the state is therefore eliminated from the simulation run. The territory that is given up is awarded to the members of the winning coalition. The territory is allocated to the states in the winning coalition in rough proportion to their contribution to the total power of the side.

\section{Power Adjustment}

The last thing that occurs in iteration is power adjustment. When the simulation run is initialized, each hexagon is given a growth rate. In the power adjustment phase, each hexagon is given additional power as calculated from its growth rate. Each state also allocates a proportion of its power to maintaining internal control. The more it allocates to this, the less the chance of a civil war involving that state, but the smaller the amount of power that state can use externally. The simulation then moves to the next iteration. ${ }^{19}$

\footnotetext{
${ }^{18}$ All states pay the same proportion of their power as a war cost.

${ }^{19}$ For this study, all runs had an iteration limit of 1000.
} 


\section{Parameters and Cases for This Study}

As shown in the appendix, a total of 29 input parameters are needed for a single run of EARTH. Given the focus of this study, the most critical parameters (which we term "experimental parameters") are those that are associated with civil wars. As well, we have a set of system- and state-level parameters that we frequently use in EARTH studies as controls. Table 3 lists the experimental and control parameters.

For this study the experimental parameters of the simulation relate to civil war. There are five specific parameters that fall into one of three categories. One category accounts for the relative frequency of civil wars (the chances of civil wars taking place in an iteration). The second category involves the effort devoted by states to prevent civil war. The third category involves the cost of fighting a civil war.

We deliberately set the civil war occurrence to 1 in order to make civil wars extremely frequent. This may not produce a "realistic" rate of civil wars (although that is a matter to be determined by comparing the results of the simulation to data of actual frequencies of civil wars). But at this point in time, the goal is to maximize the impact of civil wars on the states in the experiments.

The large number of combinations of parameter values needed from this study results in an extremely large number of cases. Given the usual number (and values) of the control variables, along with the experimental variables for this study, a total of 790 runs would be needed. Each run had an iteration limit of 1000. Given the need to look at lagged values for a state, the analysis must include the entire set of iterations for it. While interstate wars can eliminate states, civil wars create additional states; a successful civil war will result in the state being split into at least two new states. So how many cases would occur if all the sets of parameters were run? To simplify the calculations, assume that on average for the duration of each run, there are 100 states in the system. This would mean that there are about 79 million observations (790 runs $\times 1000$ iterations $\times 100$ states).

The resulting dataset would be too large to analyze in a reasonable manner. Given the necessity to include entire runs, the strategy we adopted was to create the initial parameters for all the possible runs, and then randomly select 79 sets of parameters and conduct just those runs. The resulting dataset contains "only" about 3 million observations. 
TABLE 3 Parameter values for control and civil war experimental parameters

\begin{tabular}{lc}
\hline Variable & Parameter values \\
\hline \multicolumn{1}{c}{ Control parameters } \\
Standard deviation of power estimation [2] & 10,30 \\
Standard deviation of initial power distribution [4] & $.1, .6$ \\
Share of power defeated states pay as reparations [5] & $.1,3$. \\
Sigma: relation of power ratio to war outcome [6] & 1,5 \\
Share of power all participant states pay to fight a war [7] & $.05, .2$ \\
& \\
Civil war experimental parameters & 1 \\
General imperial policy control parameter mean [13] & 0 \\
General imperial policy control distribution parameter [14] & $.2, .8$ \\
Universal civil war probability weighting parameter [16] & 1 \\
Civil war cost maximum [17] & $.2,1.0$ \\
\hline
\end{tabular}

Note: The number in brackets is the parameter number, as listed in the appendix. The appendix provides a more complete description of the meaning of each parameter.

\section{Analysis: The Impact of Civil War in a Realist World}

To shed light on the impact of civil war involvement on states in a realist world, we will use the output from the simulation runs to predict several aspects of a state's involvement in interstate war. The simplest measure is a dummy variable indicating whether or not a state became involved in an interstate war. But we wish to explore other aspects as well. For example, recent civil war experience might be associated with a greater chance of a state initiating an interstate war, but not a state being the target of another state's initiation, or vice versa. ${ }^{20}$ Each of these two additional aspects of interstate war involvement is measured by a dummy variable, with a 1 indicating the condition (initiated a war or target of a war), and a 0 indicating otherwise.

We are primarily interested in the impact of variables that tap some aspect of the civil war experience of the state on its chances of becoming involved in an interstate war. We include six variables to tap the civil war experience of the state. Two are indicators of the amount of resources that a state devotes to preventing a civil war. One is the minimum level of state resources that must be devoted to prevent the outbreak of a civil war. This is a value assigned to each state at the beginning of a run. The second variable is the actual amount of resources that the state devoted to prevent the outbreak of civil war in the previous iteration.

The four remaining variables tap aspects of the recent civil war experience of the state. The first variable is the number of civil wars won by the state over the previous five iterations. The second variable is the

\footnotetext{
${ }^{20}$ A final form of interstate war involvement would involve a state joining a conflict that escalates to war. That form of involvement is not studied in this paper.
} 
number of civil wars lost by the state over the previous five iterations. The third variable is the number of territories (hexagons) lost by the state through civil wars over the past five iterations. Finally, we include a variable that represents the amount of power lost by the state due to civil wars over the past five iterations. Each of these variables highlights a different part of the civil war experience. Across the four, we tap both the quantity and the quality of the recent civil war experience.

We also include four variables to represent the recent interstate war experience of the state. These variables are similar to the four civil war variables that represent recent civil war experience. The four variables are the number of wars won by the state in the past five iterations, the number of wars lost by the state in the past five iterations, the number of territories gained through war in the past five iterations, and the number of territories lost through war in the past five iterations. The rationale for these variables is the same as for the equivalent civil war variables; we want to tap the critical dimensions of the interstate war experience.

Five system-level control variables listed are included in the analysis; these are the control parameters listed in Table $3 .{ }^{21}$ And finally, we add three state-level variables. One is the amount of power possessed by the state in the previous iteration. The second is the actual error in the state's ability to estimate its own power. The third is the actual error in the state's ability to estimate other states' power.

Table 4 displays the results of the analysis. ${ }^{22}$ But before discussing the results, we need to say a few words about interpreting statistical significance. As we all know, one factor that affects statistical significance is the number of cases in the analysis. With over 3 million cases (!), we suggest that the default expectation is that all coefficients should reach statistical significance. In fact, we go further; we should expect all coefficients to reach high levels of statistical significance. With this expectation in mind, we turn to the coefficients for the various civil war variables for each dependent variable.

\section{Involvement in Interstate War}

There are three ways that a state can become involved in an interstate war. It can initiate a dispute that escalates to war. It can be the target of a dispute that escalates to war. It can join a dispute (as an ally) that escalates to war. The results in column 1 of Table 4 indicate that states that have high minimum maintenance costs (and, to a lesser extent, states that are currently paying high current maintenance costs) are likely to become involved in interstate wars. States are also more likely to become involved in interstate wars if they have recently won a number of civil wars. Finally, states are more likely to become involved in interstate wars if they have recently lost a lot of territory in civil wars.

\footnotetext{
${ }^{21}$ These variables have been used in a variety of studies of the EARTH simulation.

${ }^{22}$ All analysis was conducted using Stata 8.2.
} 
Previous interstate war experience also has a strong effect on war involvement. Interestingly enough, both recent war wins and war losses increase the chances of interstate war involvement (suggesting that it is the amount of recent war involvement that is important, not the outcome of the wars). Recent territorial gains from interstate wars also increase the chance of further interstate war involvement. Finally, a number of the control variables have a significant impact on a state's interstate war involvement.

In a sense, these results represent a kind of composite effect of civil wars on a state's interstate war involvement. The effects of the civil war variables may differ, depending on whether the state initiates or is the target of interstate war. It is for this reason that we ran a separate analysis on these two conditions. A comparison of the impact of the civil war variables on the two outcome variables confirms this. Only one of the variables (number of civil wars lost) has the same sign for both equations, and it is not significant in both equations.

\section{Initiation of Interstate War}

Recall the conditions under which a state becomes the initiator of a war. The state must be powerful. Being powerful increases the chances that the state will be selected as a potential initiator. And, once it is selected, being powerful makes it more likely that the state will find a target adjacent to it. Notice that the state's power in the previous iteration is positive and statistically significant, which makes sense given the conditions under which a state initiates a war

States that have high minimum maintenance costs are more likely to initiate interstate wars. Both the number of recent civil wars won by the state and the number of civil wars lost by the state are positively related to the chances of a state initiating a war. Finally, the greater the number of territories lost by the state recently, the more likely the state is to initiate an interstate war.

The findings on the civil war variables seem contradictory, but perhaps they are not. First, if a state wins a civil war, it is likely that it is powerful (in order to prevail over the portions of its territory that have revolted). ${ }^{23} \mathrm{It}$ makes sense that powerful states would be likely to initiate wars. But what about the positive relationship between losing civil wars and initiating interstate wars, and the positive relationship between the number of territories lost and initiating interstate wars? If a revolt succeeds, the result may be to create more than one new state. We are not arguing that it is a good idea for a state to lose a civil war. But a state that loses a civil war may create a "neighborhood" of weak states around its borders. In turn, this makes it more likely that if the state is selected as a potential initiator, it will find one

\footnotetext{
${ }^{23}$ Recall that a civil war occurs if a state has failed to devote enough resources to maintenance costs; the chances of a civil war occurring are not related to the power of the state per say.
} 
TABLE 4 Logit analysis: Predict interstate war

\begin{tabular}{|c|c|c|c|}
\hline & $\begin{array}{c}(1) \\
\text { State involved } \\
\text { in interstate war }\end{array}$ & $\begin{array}{c}(2) \\
\text { State initiates } \\
\text { interstate war }\end{array}$ & $\begin{array}{c}(3) \\
\text { State target } \\
\text { in interstate war }\end{array}$ \\
\hline \multicolumn{4}{|l|}{ Civil war experience } \\
\hline Minimum maintenance cost & $0.150(28.78)^{* *}$ & $0.279(28.90)^{* *}$ & $-0.018(0.69)$ \\
\hline Current maintenance cost & $0.000(2.55)^{*}$ & $-0.000(0.86)$ & $0.003(7.02)^{* *}$ \\
\hline $\begin{array}{l}\text { Number of civil wars won, } \\
\text { past } 5 \text { iterations }\end{array}$ & $0.223(59.57)^{* *}$ & $0.367(63.15)^{* *}$ & $-0.183(5.35)^{* *}$ \\
\hline $\begin{array}{l}\text { Number of civil wars lost, } \\
\text { past } 5 \text { iterations }\end{array}$ & $-0.012(0.77)$ & $0.155(6.36)^{* *}$ & $0.258(0.55)$ \\
\hline $\begin{array}{l}\text { Number of territories lost in } \\
\text { civil war, past } 5 \text { iterations }\end{array}$ & $0.040(14.02)^{* *}$ & $0.034(8.16)^{* *}$ & $-1.020(2.51)^{*}$ \\
\hline $\begin{array}{l}\text { Power lost from civil wars, } \\
\text { past } 5 \text { iterations }\end{array}$ & $0.000(1.49)$ & $-0.000(0.65)$ & $0.002(0.54)$ \\
\hline \multicolumn{4}{|l|}{ Interstate war experience } \\
\hline $\begin{array}{l}\text { Number of wars won, } \\
\text { past } 5 \text { iterations }\end{array}$ & $0.630(107.58)^{* *}$ & $1.035(130.64)^{* *}$ & $0.093(1.47)$ \\
\hline $\begin{array}{l}\text { Number of wars lost, } \\
\text { past } 5 \text { iterations }\end{array}$ & $0.443(53.58)^{* *}$ & $-0.209(9.60)^{* *}$ & $-1.610(12.73)^{* *}$ \\
\hline $\begin{array}{l}\text { Number of territories gained in } \\
\text { interstate wars, past } 5 \text { iterations }\end{array}$ & $0.024(19.54)^{* *}$ & $0.018(12.21)^{* *}$ & $-0.309(4.34)^{* *}$ \\
\hline $\begin{array}{l}\text { Number of territories lost in } \\
\text { interstate wars, past } 5 \text { iterations }\end{array}$ & $-0.002(0.65)$ & $0.009(2.27)^{*}$ & $0.060(4.57)^{* *}$ \\
\hline \multicolumn{4}{|l|}{ Control variables } \\
\hline Power, t-1 & $-0.000(1.34)$ & $0.000(5.08)^{* *}$ & $-0.020(11.43)^{* *}$ \\
\hline Error estimating own state's power & $0.449(34.56)^{* *}$ & $-0.423(18.32)^{* *}$ & $0.156(2.54)^{*}$ \\
\hline Error estimating other states' power & $-0.378(28.68)^{* *}$ & $0.271(11.65)^{* *}$ & $-0.014(0.23)$ \\
\hline $\begin{array}{l}\text { Standard deviation of power } \\
\text { estimation (system) }\end{array}$ & $-0.019(58.29)^{* *}$ & $-0.009(15.22)^{* *}$ & $-0.002(1.54)$ \\
\hline $\begin{array}{l}\text { Standard deviation of } \\
\text { power (system) }\end{array}$ & $-0.138(11.24)^{* *}$ & $-0.158(6.94)^{* *}$ & $0.283(4.62)^{* *}$ \\
\hline $\begin{array}{l}\text { Share of power defeated states } \\
\text { pay as reparations }\end{array}$ & $0.006(0.19)$ & $0.195(3.43)^{* *}$ & $-0.277(1.79)$ \\
\hline $\begin{array}{l}\text { Sigma: parameter for power ratio } \\
\text { to war outcome relationship }\end{array}$ & $-0.042(24.95)^{* *}$ & $-0.041(13.23)^{* *}$ & $0.071(7.63)^{* *}$ \\
\hline $\begin{array}{l}\text { Share of power all states pay } \\
\text { when fighting a war }\end{array}$ & $0.052(1.24)$ & $0.396(5.16)^{* *}$ & $-0.865(4.08)^{* *}$ \\
\hline Constant & $-2.990(135.50)^{* *}$ & $-4.484(112.15)^{* *}$ & $-6.621(61.09)^{* *}$ \\
\hline Observations & 3027903 & 3027903 & 3027903 \\
\hline Log likelihood & -477094.81 & -170810.75 & -32327.28 \\
\hline $\operatorname{LR} x^{2}(18 \mathrm{df})$ & 37848.70 & 3438.37 & 1207.03 \\
\hline
\end{tabular}

Absolute value of $\mathrm{z}$ statistics in parentheses.

${ }^{*}$ Significant at $5 \% ;{ }^{* *}$ Significant at $1 \%$. 
or more targets on its borders. This type of conflict might be termed a "war of reunification."

All four measures of recent interstate war experience are related to the initiation of interstate war experience. If the state has won wars recently, it is more likely to initiate a war. If it has lost wars recently, it is less likely to initiate a war. This seems reasonable; winning wars is likely to increase a state's power and make it more likely to initiate a war. War losses reduce a state's power and make it less likely that it will become a war initiator. If the state gains territories (and therefore power) it is more likely to initiate war. There is also a positive relationship between losing territories and initiating a war. This seems implausible. Considering the large number of observations, the z-statistic (although it reaches conventional levels of statistical significance) is rather small. Consequently we interpret the impact of this coefficient as essentially having no effect. All the control variables have a statistically significant impact.

\section{Target of Interstate War}

States that are targets of interstate war are weak in two ways. First, they are weak enough so that they are not selected as initiators. Second, they are weak enough that they are selected as a target by the initiator. The coefficient for the state's power in the previous iteration is negative and significant, as would be expected.

Three of the civil war variables are statistically significant (although one is only significant at the .05 level). ${ }^{24}$ The greater the current maintenance cost being paid by the state, the more likely the state is to be the target of a war. The more civil wars won by the state in the previous five iterations, the less likely the state is to become the target of a war. Finally, the greater the number of territories recently lost by the state in civil wars, the less likely the state is to be a target of a war.

High current maintenance costs weaken the state externally. The more resources a state devotes to maintenance, the fewer it has to use against other states. As well, other states are aware of this allocation. As a result, an initiator is likely to see a state with high current maintenance costs as weak and to target it. As noted above, states that win civil wars are likely to be powerful (in order to defeat the territories that are in revolt). If this is the case, then these states are unlikely to be selected as targets. Finally, if a state loses a number of territories in civil wars, as noted above, this is likely to create a band of weak states around it. It is these weak states that are more likely to be selected as targets of war.

Three of the four variables reflecting the interstate war experience of the state have a statistically significant impact on its chances of becoming the target in a war. Surprisingly, a number of recent war losses make a state less likely to be a target. The two territorial variables have expected signs. States that gain a number of territories (and hence increase their power) are less likely to be targets. States that lose a number of territories (and hence lose

\footnotetext{
${ }^{24}$ Notice that the z-statistics for the equation predicting a state being a target in war are generally smaller than for the other two equations. This is also reflected in the smaller log likelihood and chi-square for this equation.
} 
power) are more likely to become targets. As with the other dependent variables, a number of the control variables are significant.

\section{Discussion}

The analysis of the simulation runs suggests that the civil war experience of a state has an impact on its interstate war experience. Across the three equations, of the six variables included in the analysis to represent the effects of civil war, only one (power lost from civil wars over the past five iterations) fails to reach significance. There are differences in the substantive findings across the three types of war behavior (involvement, initiation, target). As well, the fit of the involvement equation is far better than for the initiation and target equations. But in spite of these differences, there are some interesting similarities across the analysis.

The six civil war variables are really three pairs, each representing a different aspect of the civil war experience. One pair deals with the allocation of power by the state to prevent the outbreak of civil war (the minimum maintenance level and the current maintenance level). A second pair deals with the number of recent civil wars experienced by the state (the number of recent civil wars won by the state, and the number of recent civil wars lost by the state). The third pair deals with the costs of recent civil wars (total power lost, total territory lost).

The results show that each of the three aspects of the civil war experience has an impact on each type of war experience. However, in most cases, only one of the two variables for a pair has an impact. And, as noted, the direction of the impact changes across the different types of interstate war experience. But the greater generality is that the results of this simulation lead to the conclusion that the civil war experience of a state has an impact on its interstate war experience in a realist world.

\section{Conclusion}

There is no question that realism is the most widely used theoretical framework in inter- national relations. But prominent realist accounts are silent about the impact of civil war in a realist world. This is no small matter because (at least beginning after the Napoleonic Wars - and the start of the Correlates of War Project war dataset) intrastate wars far outnumber interstate wars. The disparity between theory and empirical reality leads to an obvious question: What is the impact of civil wars in a realist world? This is an interesting question for theory. But how should it be explored? What is a good way to graft assumptions about civil war onto realist theory? The question is complicated by the fact that there is no single realist theory. 
It is, in fact, a collection of theories. There is overlap as we move from one conception to another. But realist thought is far from a single coherent vision. If one accepts realism, then the options for exploring and developing theory are limited. Adding elements of civil war to realism can create a much more complicated theory. Ironically, this problem can arise whether using the traditional ("classical") approach to international relations or using formal theory. Both of these approaches can only incorporate a limited number of concepts and a limited number of actors before becoming too complicated to be useful.

We believe that to explore the impact of civil wars on a system of states operating according to realist principle, we must find a way to go beyond these limitations. Per- haps traditional theory and formal theory can find ways to overcome their limitations; we encourage others to explore these avenues. But this paper has used a different tool: computer simulation. Simulations like EARTH are by no means a perfect tool. The incorporation of random elements, while relieving the researcher of the need to specify exact values for parameters, carries a price. Instead of an explicit conclusion reached by deduction (or intuition, if using a traditional approach), conclusions must refer to general tendencies.

The results of the simulation runs conducted in this paper are not definitive. But they are intriguing. Aspects of three facets of the civil war experience of a country appear to be related to its interstate war experience:

1. The amount of resources the state devotes for internal purposes to prevent the outbreak of civil war.

2. The number of civil wars recently experienced by the state.

3. The total costs of recent civil wars.

So we are left with a theoretical challenge. What is the best way to incorporate the civil war experience of a state into a realist model of the outbreak of interstate war? The beginnings of an answer may lie in the simulation results presented here. But additional work is necessary to fully answer the question. ${ }^{25}$ We hope that work goes forward.

\footnotetext{
${ }^{25}$ Despite the use of statistical analysis to clarify the results of the simulation runs, this work is a theoretical exercise, much like what would be attempted by constructing a formal model. The next step for this line of research is to conduct an empirical test with actual data to determine if the conclusions reached here correspond to behavior in the real world.
} 


\section{References}

Benoit, K. 2001. Simulation methodologies for political scientists. The Political Methodologist 10(1): $12-15$.

Bremer, S. A., and M. Mihalka. 1977. Machiavelli in machina: Or politics among hexagons. In Problems of world modeling: Political and social implications, eds. Karl Deutsch et al., 303338. Cambridge, MA: Ballinger Publishing.

Cusack, T. R., and R. J. Stoll. 1990. Exploring realpolitik: Probing international relations theory with computer simulation. Boulder, CO: Lynne Rienner.

Mearsheimer, J. 2001. The tragedy of great power politics. New York: Norton.

Morgenthau, H., and K. Thompson. [1948] 1985. Politics among nations: The struggle for power and peace, 6th ed. New York: Alfred A. Knopf.

Niou, E., and P. Ordeshook. 1991. Realism versus neoliberalism: A formulation. American Journal of Political Science 35: 481-511.

Rousseau, J.-J. 1970. Excerpts from various writings, reprinted. In The theory of international relations: Selected texts from Gentili to Treitschke, eds. M. G. Forsyth et al., 127-180. London: George Allen and Unwin.

Sarkees, M. R. 2000. The correlates of war data on war: An update to 1997. Conflict Management and Peace Science 18/1: 123-144.

Simon, M. V., and H. Starr. 1996. Extraction, allocation, and the rise and decline of states: A simulation analysis of two-level security management. Journal of Conflict Resolution 40: 272297.

Simon, M. V., and H. Starr. 2000. Two-level security management and the prospects for new democracies: A simulation analysis. International Studies Quarterly 44: 391-422.

Starr, H. 1994. Revolution and war: Rethinking the linkage between internal and external conflict. Political Research Quarterly 47: 481-507.

Stoll, R. J. 1999. Exploring international relations theory with computer simulation. In Simulation und planspiel in den sozialwissenschaften: Eine bestandsaufnahme der internationalen diskussion, eds. D. Herz and A. Blätte, 337-363. Münster, Germany: Lit Verlang.

Strassler, J. (ed.). 1998. The landmark Thucydides: A comprehensive guide to the Peloponnesian War. New York: Touchstone Books.

Waltz, K. 1979. Theory of international politics. Reading, MA: Addison-Wesley.

Wayman, F., and P. Diehl. 1994. Realism reconsidered: The realpolitik framework and its basic propositions. In Reconstructing realpolitik, eds. F. Wayman and P. Diehl, 3-26. Ann Arbor, MI: University of Michigan Press. 


\section{Appendix: Description of Parameters Necessary to run $E A R T H^{26}$}

The EARTH simulation requires that 29 parameters be specified. A brief description of each parameter and its minimum and maximum possible values is given below.

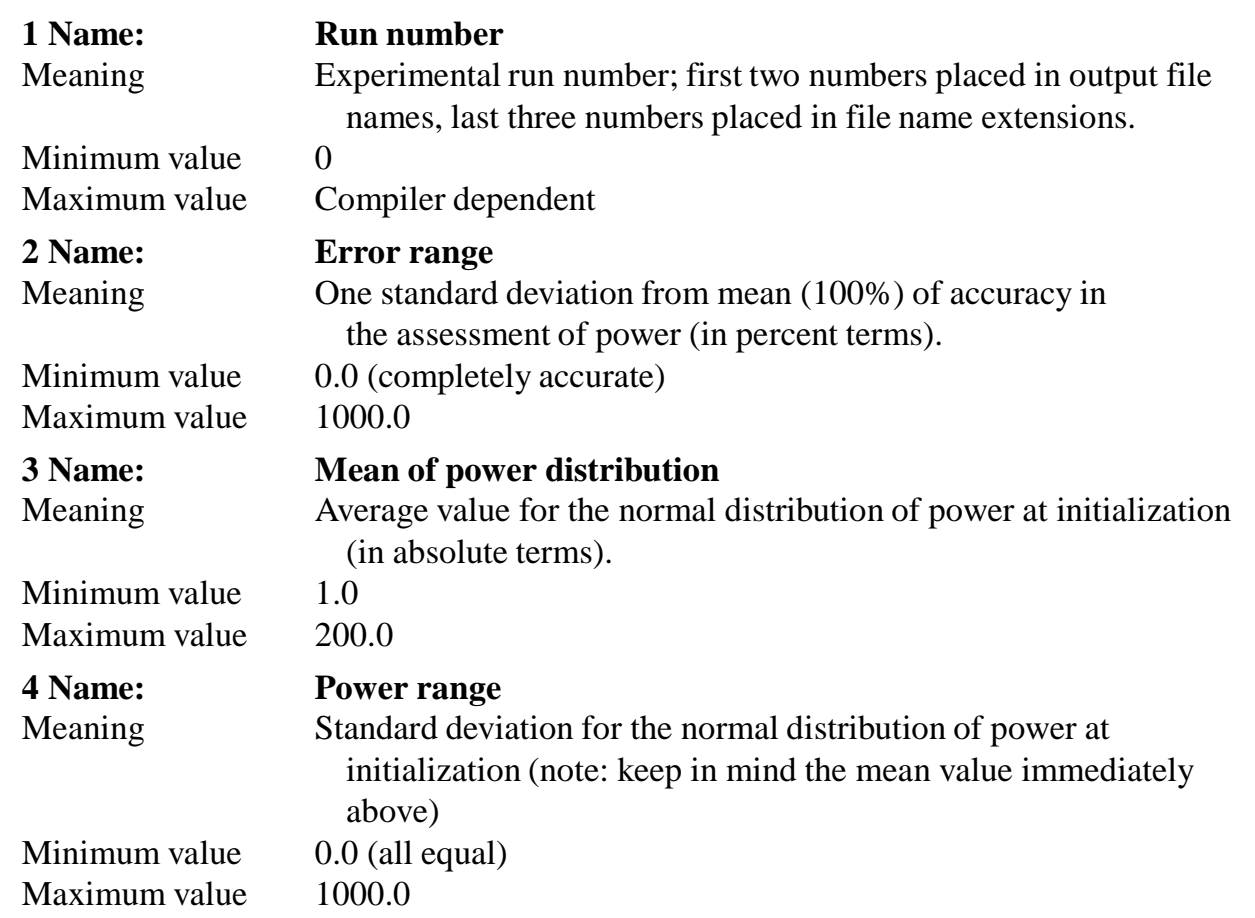

${ }^{26}$ A very similar version of this appendix appeared in Stoll (1999, 358-360). 


\author{
5 Name: \\ Meaning \\ Minimum value \\ Maximum value \\ 6 Name: \\ Meaning \\ Minimum value \\ Maximum value \\ 7 Name: \\ Meaning \\ Minimum value \\ Maximum value \\ 8 Name: \\ Meaning \\ Minimum value \\ Maximum value \\ 9 Name: \\ Meaning \\ Minimum value \\ Maximum value \\ Dependency:

\section{Reparations} \\ Proportional factor; share of power defeated states must transfer to \\ victorious states as indemnities (absolute proportional factor). \\ 0.0 (no reparations) \\ 1.0

\section{Likelihood of victory parameter, sigma} \\ Parameter controlling the shape of the curve associating power \\ ratio with the likelihood of victory. \\ 0.0 \\ 10.0

\section{Interstate war cost maximum parameter} \\ Parameter controlling the proportion of power lost by states simply \\ as a function of their involvement (absolute proportional factor). \\ 0.0 (no costs other than those associated with reparations and \\ losses of territory) \\ 1.0 \\ Seed \\ Value used to initialize random number generator (should be \\ a prime). \\ 0.0 \\ Compiler dependent

\section{Collective security states} \\ Number of states at initialization of system using collective \\ security rules. Also guides characteristics of later entries to \\ system. \\ 0 \\ Maximum of system size \\ Note that the maximum of system size minus the sum of the values \\ given for the number of collective security states, primitive \\ power seekers, and expected utility states is equal to the number \\ of states using power balancing rules.
}

10 Name:
Meaning
Minimum value
Maximum value
Dependency:

11 Name:

Meaning

Minimum value

Maximum value

Dependency:

\section{Primitive power seekers}

Number of states at initialization of system using primitive power seeking rules. Also guides characteristics of later entries to system.

0

Maximum of system size

Note that the maximum of system size minus the sum of the values given for the number of collective security states, primitive power seekers, and expected utility states is equal to the number of states using power balancing rules.

\section{Expected utility states}

Number of states at initialization of system using expected utility rules. Also guides characteristics of later entries to system.

0

Maximum of system size

Note that the maximum of system size minus the sum of the values given for the number of collective security states, primitive power seekers, and expected utility states is equal to the number of states using power balancing rules. 


\section{Name: \\ Meaning \\ Minimum value \\ Maximum value \\ Civil war occurrence interval \\ Parameter controlling relative frequency with which civil wars can occur during run. \\ 1: Effectively means that the likelihood that a civil war can occur, given that states are prone to such, is 1.0 for each iteration. \\ 9999: Civil war and associated procedures, e.g., netting control costs from power to derive effective power, shut off. Note that with 9999, model run terminates when a universal empire has been created. Any value less than 9999 permits run to continue past creation of first universal empire up until the maximum number of iterations specified (see below).}

13 Name:

Meaning

Minimum value

Maximum value

14 Name:

Meaning

Minimum value

Maximum value

15 Name:

Meaning

Minimum value

Maximum value

16 Name:

Meaning

Minimum value

Maximum value

17 Name:

Meaning

Minimum value

Maximum value

Name:

Meaning

Minimum value

Maximum value

\section{General imperial policy control parameter mean}

Mean of normal distribution of imperial control policies $(0.0=$ the average state has a control cost policy equal to that required per the universal minimum unit control parameter; see below).

$-1.0$

$+1.0$

\section{General imperial policy control distribution parameter}

Standard deviation of normal distribution of control policies (see above). In setting values, keep in mind the mean of the distribution (absolute).

0.0

1.0

\section{Minimum unit control cost parameter}

Parameter setting for proportion of weighted power of conquered territory that core must allocate to insure continuation of rule. If greater than calculated maintenance cost (function of power, time controlled, and distance from core), it overrides calculated cost; otherwise, calculated is in effect (absolute).

0.0

1.0

Universal civil war probability weighting parameter

Weight in function that produces probability score that state will confront civil war (absolute: lower than 1.0 reduces probability).

0.0

1.0

Civil war cost maximum

Parameter controlling the proportion of power lost by each side in a rebellion (absolute proportional factor).

0.0, no costs

1.0

Maintenance cost error distribution

Standard deviation of normally distributed error that characterizes states' assessments of maintenance costs required to retain control of their empires (percent value).

0.0, no error in assessments

1000.0 
18 Name:

Meaning

Minimum value

Maximum value

19 Name:

Meaning

Minimum value

Maximum value

20 Name:

Meaning

Minimum value

Maximum value

21 Name:

Meaning

Minimum value

Maximum value

22 Name:

Meaning

Minimum value

Maximum value

23 Name:

Meaning

Minimum value

Maximum value

24 Name:

Meaning

Minimum value

Maximum value

\section{Name:}

Meaning

Minimum value

Maximum value

\section{Maximum iteration}

Maximum number of iterations in experimental run.

1

Compiler dependent

\section{Mean growth rate}

Mean of normally distributed growth rates (e.g., $1=1 \%$ per iteration) (percent).

0.0

Contingent on initial power distribution, growth rate variance, and maximum iteration (set to 200.0).

\section{Growth rate variance}

Standard deviation of normally distributed growth rates (percent).

0.0

Contingent on initial power distribution, mean growth rate, and maximum iteration (set to 100.0).

\section{Interstate war cost disproportionality parameter}

Creates asymmetric war costs with stronger side suffering smaller relative costs, and vice versa.

0 : This effectively retains the basic formulation of equal war costs.

Should be a value less than interstate war cost maximum parameter (set to 100.0)

\section{Tie possible}

Permits nondecisive outcomes in interstate wars.

0 : No ties possible

1: Ties possible (Note, only 0 and 1 are permissible values for this parameter.)

\section{Tie exponent}

Parameter controlling the range of power ratios that will produce tied outcomes in interstate wars (effective only when "Tie possible" =1). Note that the greater the value, the smaller the range in which ties occur.

0.0

60000.0

\section{Map file}

Controls the writing of updated maps of system to output file and screen.

0 : No maps written

1: Map written every iteration. A number, $\mathrm{x}$, between 0 and value for "Maximum iteration" is interpreted as write every xth iteration.

\section{State history file}

Interval controlling how often state history file is written to disk 0 : Not written

1: Write characteristics of state every iteration. A number, $x$, between 0 and value for "Maximum iteration" is interpreted as write every xth iteration. 
26 Name:

Meaning

Minimum value

Maximum value

27 Name:

Meaning

Minimum value

Maximum value

28 Name:

Meaning

Minimum value

Maximum value

\section{Maximum allies}

Maximum number of allies that an initiator or target state can acquire during alliance formation process

0 (but not a good idea)

Maximum of system size

Number of rows in system

Number of rows on the map when system is initialized 1

80

\section{Number of columns in system}

Number of columns on the map when system is initialized 